\title{
DISCUSSION
}

\section{Response to Nikhil Govind - What is a knowledge system?}

\author{
GEORGE THOMAS
}

The editorial by Nikhil Govind in the Indian Journal of Medical Ethics is disturbing because of its epistemological connotations [1]. In this rejoinder, I will not address the merits or demerits of indigenous traditions in medicine, or homeopathy (which, though not an indigenous tradition is part of what is infelicitously called AYUSH - Ayurveda, Yoga, Unani, Siddha and Homeopathy). What I am concerned with here are the questions of knowledge, the scientific method, and its connotations.

For several decades now we have been hearing of a strange subject called a "Knowledge system." In fact, there is even a Centre for Excellence in Indian Knowledge Systems at the Indian Institute of Technology Kharagpur. But what exactly is a knowledge system? More pertinently, can traditional medical practices be called a "knowledge system"? Is it part of the "Indian knowledge system"? What are the specificities that differentiate this system from knowledge as we commonly understand it? [2]. No clarification is forthcoming in the editorial and so one is left to search the internet. Unfortunately, official websites under the Ministry of Education (https://iksindia.org; https://www.education.gov.in/shikshakparv/docs/

Stimulating\%20Indian\%20knowledge\%20system.pdf) are low on content and one is still left bewildered. The core curriculum as published by The Indus University is more forthcoming, but it appears to be a study of developments in the Indian subcontinent in various disciplines from historical times. All traditional medical practices, everywhere in the world, were limited in their understanding of the structure and function of the human body by the tools of science available at that time which needed to be discarded as scientific knowledge improved. The traditions of AYUSH are no different. It is a disservice to AYUSH and to epistemology to cling on to what

Author: George Thomas, (george.s.thomas@gmail.com), Orthopaedic Surgeon, Chennai, INDIA.

To cite: Thomas G. Response to Nikhil Govind - What is a knowledge system? Indian J Med Ethics. Published online first on February 7, 2022. DOI: 10.20529/IJME.2022.011

\section{Copyright and license}

(c) Indian Journal of Medical Ethics 2022: Open Access and Distributed under the Creative Commons license (CC BY-NC-ND 4.0), which permits only non-commercial and non-modified sharing in any medium, provided the original author(s) and source are credited. should be discarded under the guise that it is a "knowledge system". One wonders what psychological violence is being perpetrated on the students of these traditional medical methods by insisting on continuing to teach what is obviously wrong.

The absence of clarity on this important issue is further compounded when the author refers to the "admitted heterogeneity of the scientific method." Admitted by whom? It would have helped greatly to initiate a debate if we knew what the differences in scientific methods are in the socalled alternate "knowledge systems." Can these methods be reproduced by anyone who studies the system or are they transmitted in secret? Can these methods be tested or are we expected to take them on faith? If the latter, then surely it fails the test of what a science should be? If this "knowledge system" has a different definition of science, should we not be told what it is? It would have been very helpful if the author had clarified these points.

Is it correct to call modern medicine "Euro-American"? This is a poor description of a synthesis of medical practice which has built on the knowledge of many civilisations [3]. It is true that at the present time, the contributions from Europe and North America to science are greater than from other regions. From this, to call modern medicine "Euro- American" is rather short-sighted. The term is commonly used to contrast the so-called holistic approach of traditional systems with the so-called biomedical approach of modern medicine. The author says that modern medicine has delinked disease from any ethical or emotional context "one is ill and takes a pill" whereas in traditional systems illness is connected to larger ideas of ethical, emotional, and spiritual being. One can argue that one of the greatest contributions of the enlightenment as Kant called it [4], is to properly understand the physical and the metaphysical. Too often, these "larger ideas" have led to extreme cruelty by saying some people were not ethical or not pure and that their disease is caused by their lack of ethics and morality [5, 6]. The history of traditional medical practices all over the world is filled with horror stories caused by blaming the patient for having the disease which was said to be due to lack of moral fibre. To say that modern medicine ignores social context is simply not true. It is taught as part of the curriculum. The difficulty really is that the practice of social medicine requires policies and a cultural context to flourish. An individual doctor practising social medicine can make 
only a small impact as numerous models show [7]. Healthcare in India is extremely inegalitarian. Is this because the ethical, emotional, and spiritual aspects are neglected? It is obvious that the real reason is a lack of commitment of public funds. Countries like the United Kingdom which follow the reviled "biomedical" model have much better health outcomes. I would dearly love to hear the author's explanation of this paradox!

Regarding research, Govind is convinced that protocols must be "engaged with epistemological and textual foundations that mark our contemporary engagement with AYUSH." This is a vague statement with no clarity on what alternate protocols should be. Unless one knows what such protocols are, one cannot scrutinise them, and is not such scrutiny and debate and discussion the very foundation of sound science?

Further he says, "One can claim any regard for these systems only if one has taken some care - preferably over decades to delve into its practices as either doctor or patient/ practitioner; at all times, an attempt to engage with the actual textual traditions (even to disagree) is imperative." This statement can easily be interpreted to mean that only certain special people can have access to knowledge and critiques such as those of Krishna [8], arise out of a failure to delve deep. For example, Krishna states "Because of these handicaps, Ayurveda today retains relevance only as a system of clinical medicine and not as a system that can administer treatments based on an appraisal of the underlying pathophysiology of illnesses (internal medicine)." Will Govind accept this or does he consider it an example of the failure to understand the socalled "knowledge system"?

One of the biggest handicaps in the development of traditional medicine worldwide was its secretive nature. The secularisation of knowledge, the ability of anyone with aptitude and opportunity to pursue any branch of study has surely been one of the biggest steps in increasing human knowledge and improving societies. The attempt to forestall critiques by claiming that the critic simply does not know enough because he or she has not "engaged with the actual textual traditions" is typical of secret societies which claim special revealed knowledge and is not worthy of a scientist in any discipline.

Modern science has been criticised for not providing an answer to the meaning of human life. It has also been criticised because the technology and inventions that have arisen out of understanding in the natural sciences has not always improved human society. One can certainly accept that these criticisms are true and welcome any approach which would address them. But will nostalgia and a regression to the past help? It is quite unlikely. For the majority of humankind, life in the past was nasty, brutish and short.

Max Weber pointed out that rationalisation and democratisation of society lead inevitably to the need for bureaucracies and these bureaucracies lead to dehumanisation in the interaction of the individual with the organs of society. One of the biggest criticisms of modern medicine is that it is dehumanised, it lacks the personal touch, that hospitals are disease palaces with little concern for the individual. Following Weber, we can say that these problems arose out of a pursuit of efficiency, the iron cage of rationalisation [9]. This is quite simple to understand.

Govind seems to suggest that these problems arise from the scientific method itself and a return to a different "knowledge system" will be a way forward. At present in India we are witnessing state sponsorship for a return to regressive social and cultural practices. One element in this playbook is support for obscurantist practices dressed up as science and kept beyond the pale of criticism by claiming that they follow a different "knowledge system" without ever defining what that system is. The publication of a calendar by The Centre for Indian Knowledge Systems filled with dubious scientific claims is typical of this approach [10]. Conflating the philosophical contributions by people from the Indian subcontinent with knowledge in natural science, much of it now obsolete, and calling it a "knowledge system" is not merely wrong, it is harmful. Science alone will not ensure a better society, but it is certainly a help. Obscurantism in the name of an "alternate knowledge system" is most certainly a hindrance and must be resolutely opposed.

\section{References}

1. Govind N. Listening to diverse knowledge systems. Indian J Med Ethics. 2022 Jan-Mar; 7(1) NS: 5-7.Doi:10.20529/IJME.2022.002

2. Stanford Encyclopedia of Philosophy. The Analysis of Knowledge. Revised 2017 Mar 17[cited 2022 Jan 26]. Available from: https:// plato.stanford.edu/entries/knowledge-analysis/

3. Robson Thomson WA. The history of medicine. Brittanica.com. date unknown [cited 2022 Jan 26]. Available from: https:// www.britannica.com/science/history-of-medicine

4. Kant I. What is Enlightenment? Columbia.edu. Transl: Smith MC. Date unknown [cited 2022 Jan 26]. Available from: http:// www.columbia.edu/acis/ets/CCREAD/etscc/kant.html

5. Washington HA. Medical Apartheid: The Dark History of Medical Experimentation on Black Americans from Colonial Times to the Present. Anchor; Reprint 2008.528 pgs.

6. Krithi S, Karunakaran K, Jeyalydia J, Parthesarathy R, Sundararaman T. Discourses around Stigma and Denial in the COVID-19 Pandemic A Case Study from Tamil Nadu. Econ Pol Wkly. 2022 Jan 22 [cited 2022 Jan 26]; 57(4). Available from: https://www.epw.in/journal/ 2022/4/perspectives/discourses-around-stigma-and-denial-covid19.html

7. Alcorn T. From Zero to 50,000: The Making of a Community Health Program in Rural India. A Q\&A with pediatric oncologist and Jan Swasthya Sahyog cofounder Yogesh Jain. 2021 Jul 12[cited 2022 Jan 26]. Available from: https://www.thinkglobalhealth.org/article/zero50000-making-community-health-program-rural-india

8. Krishna G L. Ayurveda awaits a new dawn. Indian J Med Ethics. 2022 Jan-Mar;7(1): 16-21.Doi:10.20529/JJME.2021.093

9. Feenberg A. Escaping the Iron Cage, or, Subversive Rationalization and Democratic Theory. In: Schomberg R, ed., Democratising Technology. Ethics, Risk and Public Debate. Tilburg: International Centre for Human and Public Affairs, 1998 [cited 2022 Jan 26], pp. 115. Available from: https://www.sfu.ca/ andrewf/books/ Escaping_Iron_Cage.pdf

10. Rajendran C P. Distorting history through a calendar. The Hindu. 2022 Jan 26[cited 2022 Jan 26]. p 15. Available from: https:// www.thehindu.com/opinion/op-ed/distorting-history-through-acalendar/article38325449.ece 